\title{
Registration of amiloride in South Africa: Cutting the Gordian knot
}

B L Rayner, ${ }^{1}$ MB ChB, MMed (Internal Medicine), FCP (SA), PhD; J D Spence, ${ }^{2}$ MD, FRCPC (Neurology), FRCPC (Internal Medicine), FAHA; A Bryer, ${ }^{3}$ MB BCh, MMed (Neurology), FCP (SA), FCNeurol (SA) PhD; M T Mpe, ${ }^{4}$ MB ChB, FCP (SA), MMed (Internal Medicine)

\author{
${ }^{1}$ Division of Nephrology, Department of Medicine, Faculty of Health Sciences, University of Cape Town and Groote Schuur Hospital, \\ Cape Town, South Africa \\ ${ }^{2}$ Neurology and Clinical Pharmacology, Western University, London, Canada \\ ${ }^{3}$ President, South African Stroke Society, and Division of Neurology, Department of Medicine, Faculty of Health Sciences, \\ University of Cape Town and Groote Schuur Hospital, Cape Town, South Africa \\ ${ }^{4}$ President, Southern African Hypertension Society, South Africa
}

Corresponding author: B L Rayner (brian.rayner@uct.ac.za)

\begin{abstract}
Amiloride is an antagonist of the renal tubular epithelial sodium channel (ENaC). As such, it is a diuretic that is both potassium and magnesium sparing. It is used for the treatment of potassium depletion and hypertension, and is the specific therapy for hypertension due to overactivity of the $\mathrm{ENaC}$ (Liddle syndrome and several additional genetic causes of the Liddle phenotype - low renin and low aldosterone). It is listed as a World Health Organization essential drug, but has never been registered in South Africa (SA) and can therefore only be prescribed under a Section 21 application to the SA Health Products Regulatory Authority (SAHPRA) on a case-by-case basis. In SA, $>50 \%$ of patients treated for hypertension are not controlled. In the USA, the Reasons for Geographic and Racial Differences in Stroke (REGARDS) study reported that African Americans are more likely to be diagnosed with hypertension, more likely to be treated, more likely to be treated intensively, and less likely to achieve blood pressure (BP) control. Although the reasons are complex, studies show that 10 - 20\% of blacks may carry the Liddle phenotype. Observational data and a controlled clinical trial done in three African countries have shown that these patients respond to amiloride and not to conventional guideline-based antihypertensive treatment. The former is likely to result in a significant reduction in cardiovascular, stroke and kidney morbidity and mortality, because of improved BP control. Amiloride is very unlikely to ever be registered in SA, as it was first developed $>50$ years ago, and SAHPRA regulations prevent widespread prescription of this essential drug. This is a classic Gordian knot that requires a novel approach from authorities to sever the knot and improve the health of many South Africans.
\end{abstract}

S Afr Med J 2019;109(9):632-634. https://doi.org/10.7196/SAMJ.2019.v109i9.14158

Cutting the Gordian knot is a commonly used metaphor for solving an intractable problem that is resolved easily by a radically different approach. The legend dates to 333 BC when Alexander the Great marched into the city of Gordium in modern-day Turkey. On arriving, he encountered a wagon with its yoke tied in a knot, which no one could unfasten. After wrestling with the knot for some time, Alexander drew his sword and sliced the knot in half, so releasing the wagon from the yoke.

South Africa (SA) (and Africa) faces a similar problem in relation to the registration of amiloride for treatment of resistant or severe hypertension in the black African and mixed ancestry populations; there needs to be a radical new approach to address this pressing issue.

Amiloride is a potassium-sparing diuretic that blocks the epithelial sodium channel $(\mathrm{ENaC})$ in the collecting duct of the kidney, resulting in natriuresis and retention of potassium and magnesium. ${ }^{[1]}$ The $\mathrm{ENaC}$ is the final regulator of sodium balance in the kidney and therefore plays a crucial role in sodium regulation and blood pressure (BP) control. ${ }^{[2]}$ The main indication for amiloride is for the treatment of hypertension; it is listed as a World Health Organization (WHO) essential drug. ${ }^{[3]}$ Although developed $>50$ years ago, amiloride did not gain widespread use in the treatment of hypertension and is hardly mentioned in most hypertension guidelines.
Amiloride alone has never been registered in SA, but is available in a combination tablet with hydrochlorothiazide (HCTZ) (amiloride $5 \mathrm{mg}$, HCTZ $50 \mathrm{mg}$ ). Although this combination tablet may lower blood pressure, there are two problems: (i) the dose of HCTZ is too high, with a propensity for electrolyte abnormalities at full dose that can be severe and life threatening; ${ }^{[1]}$ and (ii) if half the dose is used to minimise electrolyte abnormalities, the dose of amiloride $(2.5 \mathrm{mg})$ is insufficient to adequately target the $\mathrm{ENaC}$. As pure amiloride has never been registered, it can only be prescribed on a case-by-case basis, approved by the SA Health Products Regulatory Authority (SAHPRA) under a Section 21 application.

Targeting the $\mathrm{ENaC}$ is critically important in black Africans to control severe or resistant hypertension. Given the number of patients affected, this is not feasible when approval of the drug is required on a case-bycase basis. The reasons for targeting the $\mathrm{ENaC}$ in black hypertensive patients are a tale of two research groups working independently on two different continents, coming to the same conclusion, and then collaborating to perform a clinical trial that confirmed this approach.

\section{The tale of amilloride}

\section{Cape Town, South Africa}

The principal author (BLR) is a nephrologist and hypertension expert, who started working in the Hypertension Clinic at Groote 
Schuur Hospital, Cape Town, SA, in 1994. He was struck by the number of patients with severe drug-resistant hypertension, despite good medication adherence. Based on the work of Richard Gordon from Brisbane, Australia, who found that the prevalence of primary aldosteronism (PA) in their locality was $12 \%,{ }^{[4]}$ the aldosteronerenin ratio to screen patients with drug-resistant hypertension was implemented by him. Thirty-two percent of patients had evidence suggestive of primary aldosteronism, and the introduction of spironolactone made a dramatic difference to $\mathrm{BP}$ control in these patients. ${ }^{[5]}$

Furthermore, during a screening programme to establish normal ranges of aldosterone and renin in three SA population groups (white, mixed ancestry and black), the mean plasma renin activity (PRA) and plasma aldosterone levels were significantly lower in black and mixed ancestry patients than in white patients, despite similar salt intake. ${ }^{[6]}$ Low PRA and plasma aldosterone levels are the hallmark of the Liddle syndrome, which is an inherited condition due to mutations in the beta chain of the ENaC. ${ }^{[7]}$ This results in excess expression of $\mathrm{ENaC}$ on the tubular cells of the collecting duct, resulting in increased sodium reabsorbtion despite suppressed aldosterone. The $\mathrm{ENaC}$ is a crucial site of salt balance and hence of BP control, as it is the final regulator of sodium balance in the kidney. ${ }^{[2]}$

Consequently, the entire gene for the sodium channel epithelial beta (SCNN1 $\beta$ ) subunit of the $\mathrm{ENaC}$ was sequenced and a novel single nucleotide polymorphism (SNP) (p.Arg563Gln or R563Q) was identified. ${ }^{[8]}$ It was later shown to be associated with low reninand low aldosterone-related hypertension in indigenous southern African and Cape mixed ancestry population groups; ${ }^{[8]}$ there was a strong association with hypertension and the p.Arg563Gln mutation in blacks living in urban areas, and $5 \%$ of hypertensives were carriers. ${ }^{[9]}$ In a kindred study, the p.Arg563Gln mutation strongly associated with hypertension, ${ }^{[10]}$ and patients with severe hypertension carrying this mutation responded exceptionally well to amiloride, a specific inhibitor of $\mathrm{ENaC} .{ }^{[9]}$ The prevalence of the p.Arg563Gln mutation was $20 \%$ in the Khoi-San population, who are hunter-gatherer people living in the Kalahari desert, suggesting that this was the population of origin (for this variant) and may have offered survival advantage in a sodium-restricted environment. ${ }^{[9]}$ In addition to true Liddle syndrome due to variants of $\mathrm{ENaC}$, there are variants of at least 5 other genes that increase the activity of $\mathrm{ENaC}$, resulting in a Liddle phenotype (GRK, NEDD4L, CYP4A11, NPPA, UMOD and perhaps others). ${ }^{[11]}$ Therefore, although the prevalence of true Liddle syndrome may be only $\sim 6 \%$ among resistant hypertensives in Cape Town, the prevalence of a Liddle phenotype, also selectively responsive to amiloride, is apparently much higher, as discussed below.

\section{London, Canada}

The second author (JDS) is a neurologist and clinical pharmacologist in London, Ontario, Canada, with a special interest in hypertension and stroke prevention. He examined patients from an African American community in Buxton, near London, who were descendants of slaves who had escaped to Canada in the 1800s. Blacks were much more likely to have a low plasma renin, which at the time was attributed to primary aldosteronism, mostly due to bilateral adrenocortical hyperplasia (plasma aldosterone levels were then not available; therefore, the Liddle phenotype was unrecognised in that clinic population)..$^{[12]}$

In 2006, Spence ${ }^{[13]}$ suggested that physiologically individualised therapy based on phenotyping with plasma renin and aldosterone had the potential to eliminate or at least markedly diminish the racial disparities in hypertension and stroke in the USA. A treatment algorithm was developed (Table 1), which resulted in excellent control rates for hypertension and a marked reduction in stroke. ${ }^{[14]}$

\section{Physiologically individualised therapy in Africa}

A randomised clinical trial was implemented to test this hypothesis in Africa, and evidence supporting this approach is available in hypertension clinics in Nigeria, Kenya and SA. ${ }^{[15]}$ Patients whose BP was not controlled to $<140$ systolic $\mathrm{mmHg}$ or 90 diastolic $\mathrm{mmHg}$ were allocated to usual care (UC) v. physiologically individualised therapy (PhysRx).

In the overall study, control of both systolic and diastolic BP was obtained in $11.1 \%$ of UC-treated patients v. $50.0 \%$ of PhysRx-treated patients $(p<0.0001)$. Systolic control was achieved in $13.9 \%$ of UC patients v. $60.3 \%$ of PhysRx patients $(p<0.0001)$; and diastolic control was achieved in $36.1 \%$ of UC patients v. $67.2 \%$ of PhysRx patients ( $p=0.003)$. At the Nigerian site, where patients were randomised and conditions were more similar to those in North America, systolic control was obtained in $15 \%$ of UC patients v. $85 \%$ of PhysRx patients ( $p=0.0001$ ); diastolic control in $45 \%$ of UC patients v. $75 \%$ of PhysRx patients $(p=0.11)$; and control of both systolic and diastolic pressure in $15 \%$ of UC patients v. $75 \%$ of PhysRx patients $(p<0.0001)$, even though the renal function was worse at that site. The major difference in medication change during the study was with amiloride; at the end of the study amiloride was being taken by $19 \%$ of PhysRx patients v. only $2.8 \%$ of UC patients $(p=0.02)$. This indicates that $19 \%$ of these patients with resistant hypertension had a Liddle phenotype.

Furthermore, in this study, genetic analysis of candidate genes was undertaken in those with the Liddle phenotype. Most patients had variants of several different genes affecting $\mathrm{ENaC}$ function. Among those with a primary aldosteronism phenotype, all patients had variants of aldosterone synthase. ${ }^{[16]}$ In 2019, Spence hypothesised that

Table 1. Physiologically individualised therapy based on renin/aldosterone profile

\begin{tabular}{llll}
\hline & & $\begin{array}{l}\text { Liddle phenotype } \\
\text { (due to variants of ENaC or } \\
\text { genes affecting its function*) }\end{array}$ & Renal/renovascular \\
\hline Renin & Primary aldosteronism & Low & High \\
Aldosterone & High & Low & High \\
Primary treatment & Aldosterone antagonist & Amiloride & Angiotensin receptor blocker or renin \\
& (spironolactone or eplerenone) & & inhibitor (rarely revascularisation) \\
& Amiloride for men, where & & \\
& eplerenone is not available & & \\
& (rarely surgery) & & \\
${ }^{*} G R K, N E D D 4 L, C Y P 4 A 11, N P P A, U M O D$, and perhaps others. & &
\end{tabular}


some patients may have variants predisposing to both inappropriate aldosterone secretion and overactivity of the ENaC. For identification of physiologically appropriate therapy, it would be more practical to do phenotyping by measuring plasma renin and aldosterone than sequencing the beta chain of the $\mathrm{ENaC}$ and other genes that increase $\mathrm{ENaC}$ activity.

\section{Case for amiloride in South Africa}

In SA, hypertension is one of the leading causes of death, and $50 \%$ of treated hypertensive patients are not controlled. ${ }^{[17]}$ In the USA, the Reasons for Geographic and Racial Differences in Stroke (REGARDS) study showed that African Americans are more likely to be diagnosed with hypertension, more likely to be treated, more likely to be treated intensively, and less likely to achieve BP control. ${ }^{[18]}$ Although the reasons are complex, including poor adherence and lack of access to antihypertensive medication, it is now apparent that a large proportion of uncontrolled hypertension in blacks is due to polymorphisms in genes that increase $\mathrm{ENaC}$ function, resulting in salt and water retention, with suppressed renin and aldosterone. Amiloride is the specific treatment for uncontrolled hypertension. This has been demonstrated in an uncontrolled study in SA and more importantly in the randomised trial of physiological individualised treatment of resistant hypertension, as discussed above. ${ }^{[9,15]}$ Triamterene also blocks the ENaC and is available in SA in combination with HCTZ $25 \mathrm{mg}$. It causes renal casts in more than half of the patients - thought to be due to interstitial nephritis - and is not recommended. ${ }^{[19]}$

Given that it is estimated that $>5 \%$ of black hypertensives in SA have proven mutations of the $\mathrm{ENaC}$ and $10-20 \%$ have resistant hypertension due to the Liddle phenotype, it is simply not feasible to seek individual approval for the number of patients affected. Requests to register amiloride by the company that originally developed it, have not been successful, presumably because there would be no patent protection. Generic companies also cannot import amiloride unless it has been registered by the company that produced the original brand.

Amiloride is registered in SA in the combination tablet Amiloride Co (HCTZ $50 \mathrm{mg}$ /amiloride $5 \mathrm{mg}$ ), and approaches to a colleague linked to SAHPRA to use this as a basis for expedited registration were considered inappropriate. The combination tablet has too little amiloride and too much HCTZ to be clinically useful in adults with resistant hypertension. The studies demonstrating efficacy of amiloride used $10 \mathrm{mg}$ daily; with the combination tablet, administration would result in $100 \mathrm{mg}$ daily of HCTZ, with a high risk of depletion of sodium, potassium and magnesium.

Therefore, we have an important need for amiloride tablets without HTCZ to administer to black patients with severe and resistant hypertension. We are unable to provide these on a meaningful scale to benefit the patients. The regulations of SAPHRA prevent this, resulting in a classic Gordian knot that needs to be cut. The pen is said to be mightier than the sword, so unlike Alexander the Great, the knot can be cut with the stroke of a pen to modify Section 21 regulations related to essential drugs not registered in SA.

\section{Conclusions}

Amiloride is a WHO essential drug that has been registered in SA, but only in a combination product with too high a dose of HCTZ. Use of amiloride in black and mixed ancestry patients with severe and resistant hypertension is highly likely to improve BP control, with resultant reduction in cardiovascular, stroke and kidney morbidity and mortality.

Declaration. None.

Acknowledgements. None.

Author contributions. BLR wrote the manuscript, which was critically reviewed by all the authors.

Funding. None.

Conflicts of interest. Dr J D Spence is a consultant to Amgen and Orphan Technologies, an officer of Vascularis Inc., and has received lecture fees from Pfizer and Bristol-Myers Squibb. Prof. B L Rayner has received lecture fees from Servier, Sanofi, Novartis, Cipla, Litha, AstraZeneca and Boehringer Ingelheim.

1. Diuretics. In: Gibbon C, ed. South African Medicines Formulary. 6th ed. Cape Town: South African Medical Association Health and Medical Publishing Group, 2003:138-143.

2. Lindhorst J, Alexander N, Blignaut J, Rayner B. Differences in hypertension between blacks and whites: An overview. Cardiovasc J Afr 2007;18(4):241-247.
.

3. World Health Organization. Model Lists of Essential Medicines. http://www.who.int/medicines . World Health Organization. Model Lists of Essential
publications/essentialmedicines/en/ (accessed 2 May 2019).

publications/essentialmedicines/en/ (accessed 2 May 2019).
Gordon RD, Ziesak MD, Tunny TJ, Stowasser M, Klemm SA. Evidence for primary hyperaldosteronism Gordon RD, Ziesak MD, Tunny TJ, Stowasser M, Klemm SA. Evidence for primary hyperaldosteronism
may not be uncommon - twelve percent incidence among antihypertensive drug trial volunteers. Clin Exp Pharmacol Physiol 1993;20(5):296-298.

5. Rayner BL, Opie LH, Davidson JS. Aldosterone/renin ratio as a screening test for primary aldosteronism. S Afr Med J 2000;90(4):387-394.

6. Rayner BL, Meyers JE, Opie LH, Trinder YA, Davidson JS. Screening for primary aldosteronism - norma ranges for aldosterone and renin in three South African groups. S Afr Med J 2001;91(7):594-599.

7. Lifton RP, Gharavi AG, Geller DS. Molecular mechanisms of human hypertension. Cell 2001;104(4):545-556.

8. Rayner BL, Owen PE, King JA, et al. A new mutation, R563Q, of the beta subunit of the epithelial sodium channel associated with low-renin, low-aldosterone hypertension. J Hypertens 2003;21(5):921-926 https://doi.org/10.1097/01.hih. $0000059009.82022 .9 \mathrm{~b}$

9. Jones ES, Owen EP, Rayner BL. The association of the R563Q genotype of the ENaC with phenotypic variation in southern Africa. Am J Hypertens 2012;25(12):1286-1291. https://doi. phenotypic variation in

10. Jones E, Owen E, Davidson J, van der Merwe L, Rayner B. The R $563 \mathrm{Q}$ mutation of the epithelial sodium

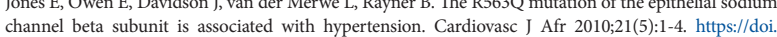
org/10.5830/CVJA-2010-084

11. Spence JD, Rayner BL. Hypertension in Blacks: Individualized therapy based on renin/aldosterone phenotyping. Hypertension 2018;72(2):263-269. https://doi.org/10.1161/HYPERTENSIONAHA.118.11064

12. Spence JD. Physiologic tailoring of therapy for resistant hypertension: 20 years' experience with stimulated renin profiling. Am J Hypertens 1999;12(11):1077-1083. https://doi.org/10.1016/S0895-7061(99)00154-5 13. Spence JD. Individualized therapy for hypertension. Hypertension 2006;47(3):e11.

14. Spence JD. Antihypertensive drugs and prevention of atherosclerotic stroke. Stroke 1986;17(5):808-810.

15. Akintunde A, Nondi J, Gogo K, et al. Physiological phenotyping for personalized therapy of uncontrolled hypertension in Africa. Am J Hypertens 2017;30(9):923-930. https://doi.org/10.1093/ajh/hpx066

16. Jones ES, Spence JD, Mcintyre AD, et al. High frequency of variants of candidate genes in black Africans with low renin-resistant hypertension. Am J Hypertens 2017;30(5):478-483. https://doi. org/10.1093/ajh/hpw167

17. Berry KM, Parker WA, Mchiza ZJ, et al. Quantifying unmet need for hypertension care in South Africa through a care cascade: Evidence from the SANHANES, 2011 -2012. BMJ Glob Health 2017;2(3):e000348. through a care cascade: Evidence from the SANH

18. Howard G, Prineas R, Moy C, et al. Racial and geographic differences in awareness, treatment, and control of hypertension: The REasons for Geographic And Racial Differences in Stroke study. Stroke 2006;37(5):1171-1178. https://doi.org/10.1161/01.STR.0000217222.09978.ce

19. Spence JD, Wong DG, Lindsay RM. Effects of triamterene and amiloride on urinary sediment in hypertensive patients taking hydrochlorothiazide. Lancet 1985;2(8446):73-75

Accepted 3 June 2019. 